\title{
Politización miliciana en las compañías de pardos y morenos de Santa Fe: centralismo porteño, autonomía provincial y federalismo artiguista. 1810-1815
}

\author{
The militia politicization in Santa Fe's companies of pardos \\ and morenos: Buenos Aires centralism, provincial autonomy \\ and federalism of Artigas. 1810-1815
}

Ariel Viola

Universidad Nacional del Litoral

DOI: https://doi.org/10.25032/crh.v5i9.4

Recibido: 3/11/2019

Aprobado: 30/11/2019

Resumen. La historiografía sobre la participación armada de africanos y afrodescendientes durante las guerras de independencia ha crecido en los últimos años. Los estudios que trataron el Río de la Plata se han concentrado preferentemente en Buenos Aires y Montevideo, pero no en Santa Fe, territorio clave, interconectado con ambos, por donde atravesaban disputas políticas en torno a la revolución: centralismo porteño, federalismo artiguista, autonomía provincial. Estos modelos políticos interpelaban a los soldados pardos y morenos que fueron reclutados en las fuerzas de Santa Fe. Dentro de las compañías negras se debatían estas ideas, como lo manifiestan los dos casos que se analizan en este trabajo: la circulación de un memorial entre los pardos y morenos auxiliares al Ejército del Perú en 1813 y el acuartelamiento de la milicia cívica de pardos libres en 1815, episodios que forman parte de lo que se denomina politización miliciana.

\footnotetext{
${ }^{1}$ Este trabajo ha sido desarrollado en el marco del programa de investigación dirigido por Magdalena Candioti: PICT 2017-3306 "Esclavitud, Emancipación y ciudadanía en el Río De La Plata. Estudio Comparado de Africanos Y Afrodescendientes en Buenos Aires, el Litoral, Cuyo y Córdoba (1776-1860)".

Agradezco con cariño a Magdalena, por salvar mi distancia con los documentos y por acercarme a esta historia.
} 
Palabras clave: Santa Fe, guerras de independencia, pardos y morenos, politización miliciana.

Abstract. The historiography of the armed participation of Africans and Afrodescendants during the wars of independence has grown in recent years. The studies that dealt with Río de la Plata have preferably concentrated in Buenos Aires and Montevideo, but not in Santa Fe, a key territory, interconnected with both, where they were going through political disputes around the revolution: Buenos Aires centralism, federalism of Artigas, provincial autonomy. These political models questioned the pardos and morenos soldiers who were recruited into the forces of Santa Fe. Within the black companies these ideas were discussed, as evidenced by the two cases analysed in this work: the circulation of a memorial among the pardos and morenos auxiliary to the Army of Peru in 1813 and the quartering of the civil militia of free pardos in 1815, episodes that are part of what is called militia politicization.

Keywords: Santa Fe, independence wars, pardos and morenos, militia politicization.

\section{Introducción: un diálogo con la historiografía.}

Los estudios sobre el reclutamiento masivo de las poblaciones del Río de la Plata tras la revolución de 1810 se han multiplicado en las últimas dos décadas. Publicaciones fundamentales han contribuido a delinear una bibliografía sobre la militarización de los sectores subalternos en los tiempos de guerra revolucionaria (Aramburo; Bragoni; Di Meglio A y B; Fradkin A y B; Mata; Rabinovich A), contribuyendo a una perspectiva más social del tema.

En 2010, particularmente, entre estas compilaciones se propuso un tratamiento específico de la participación de africanos y afrodescendientes en las milicias y ejércitos de línea que se levantaron a partir de 1810 en las ciudades de las Provincias Unidas del Río de la Plata: Negros de la Patria, libro editado por Silvia Mallo e Ignacio Telesca, constituye una historiografía -o al menos una sistematización- para la temática. Su recorte atiende a la participación de negros en las guerras de independencia, haciendo hincapié en la introducción de esclavos $\mathrm{y}$, fundamentalmente, logrando una regionalización de la cuestión y el establecimiento de una transversalidad en el proceso de militarización y politización en los diferentes territorios del anterior virreinato 
(Guzmán 12). Entre los capítulos, algunos se dedican al análisis de las formas de acción política entre los miembros de la tropa, en diferentes espacios, a veces fuera del área dominante de lo que constituía la Gobernación de Buenos Aires.

Respecto al Litoral conocemos menos sobre la movilización militar y la historia de sus unidades negras, ya que la mayoría de los trabajos se han concentrado en la ciudad de Buenos Aires. Incluso cuando se toma una perspectiva rioplatense, no se suelen inspeccionar archivos de otras provincias y, muchas veces, no se tiene en cuenta que los pueblos del Litoral ya eran independientes en 1815, de la misma manera que su dirección militar.

Es imprescindible hacer un recorrido por los estudios que han analizado, históricamente, a los africanos y afrodescendientes de Santa Fe a principios del siglo XIX. La historiografía local, desde mediados del siglo XX, resaltó un supuesto trato benigno de los amos santafesinos sobre la "esclavatura", sin reparar en el sostenimiento de un sistema de esclavización que los sometía a una condición cautiva y servil. ${ }^{2}$ Por otro lado, explicaba la relación conflictiva entre las autoridades coloniales de Santa Fe y los habitantes originarios del territorio, por la ocupación del espacio, como "el problema del indio".3 Por tanto, vinculada a la historia política, esta historiografía no se detenía en la comprensión de las configuraciones étnicas, sociales y de género de los grupos subalternos de la comunidad colonial de Santa Fe.

A principios del presente siglo, María del Rosario Baravalle realizó un trabajo más profundo y específico sobre la esclavitud en Santa Fe, abarcando las problemáticas del tráfico y las condiciones de vida de las negras y los negros esclavizados (79-97). En los últimos años, Magdalena Candioti contribuyó a producir una renovación historiográfica en el análisis de la población africana y afrodescendiente santafesina en el siglo XIX, concentrándose en el impacto de las leyes de abolición de la esclavitud en

\footnotetext{
${ }^{2}$ Ver Agustín Zapata Gollán, Los Negros. Revista América, Santa Fe, 1978; Catalina Pistone, La esclavatura negra en Santa Fe. Junta Provincial de Estudios Históricos, Santa Fe, 1996.

${ }^{3}$ Ver Manuel Cervera, Santa Fe (1810-1820), en Historia de la Nación Argentina (desde los orígenes hasta la organización definitiva en 1862), Levene, R. (Dir.), Buenos Aires, El Ateneo, 1946; Bernardo Alemán y Federico Cervera, "Libro I: El problema del indio - Fronteras - Fortines y Milicias santafesinas", en Historia de las Instituciones de la provincia de Santa Fe, Tomo III, Santa Fe, 1970; Leoncio Gianello, Historia de Santa Fe. Plus Ultra, Santa Fe,1978; Federico G. Cervera, Las baterías de Santa Fe. 1810-1814. Imprenta oficial, Junta Provincial de Estudios Históricos, Santa Fe, 1982.
} 
Santa Fe.4 Aquellos textos sirvieron para actualizar la temática, habiendo pasado un tiempo considerable.

En 2016, Candioti escribió sobre los habitantes pardos y morenos registrados en las actas parroquiales y los padrones de 1816/1817 y de 1823, pudiendo obtener resultados sobre la proporción de africanos y afrodescendientes, libres y esclavos, en la sociedad de Santa Fe. Para mediados de la década de 1810 calculó que la población no blanca - pardos, morenos, negros, chinos e indios- se aproximaba al 50\% de los habitantes de la ciudad; el grupo pardos y morenos, exclusivamente, representaba un 40\% del total; y entre ellos, un 30\% eran esclavos, es decir, el 11,80\% de la población. 5 (Candioti A 107). Al abordar los rescates militares de esclavos consideró que "queda pendiente un trabajo sistemático sobre los batallones de pardos y morenos de la provincia, su composición, su dinámica y su participación social y militar”. (Candioti A 115). 6

A partir de dicho estado historiográfico, el cometido de este artículo es acercarse a prácticas y discursos emprendidos por soldados de las compañías de pardos y morenos que logren poner de manifiesto la circulación de ideas políticas y posibles márgenes de acción organizados entre los miembros de la tropa. Poniendo a Santa Fe como epicentro, se pretende alcanzar un marco más amplio, correspondiente a un

\footnotetext{
${ }^{4}$ Ver publicaciones de Magdalena Candioti: Regulando el fin de la esclavitud. Diálogos, innovaciones y disputas jurídicas en las nuevas repúblicas sudamericanas. 1810-1830. Jahrbuch für Geschichte Lateinamerikas, vol. 52, 2015. pp. 149-172; Abolición gradual y libertades vigiladas en el Río de la Plata. La política de control de libertos de 1813. Corpus. Archivos Virtuales de la Alteridad Americana, vol. 6, 2016 pp. 1-14; Hacia una historia de la esclavitud y la abolición en la ciudad de Santa Fe, 1810-1853, en Cartografías latinoamericanas. Guzmán, F.; Geler, L.;Frigerio, A. (Ed.), Buenos Aires, Biblos, 2016; Manumisiones negociadas y libertades frágiles en el Río de la Plata. Santa Fe, 1810-1853, en Formas de liberdade: gratidão, condicionalidade e incertezas no mundo escravista nas Américas / organização Jonis Freire, María Verónica Secreto. - 1. ed. - Rio de Janeiro: Mauad X: Faperj, 2018.

${ }^{5}$ Para un análisis pormenorizado de la población negra y mestiza de Santa Fe a principios del siglo XIX ver: Magdalena Candioti et al, Esclavos, libres y libertos en la ciudad de Santa Fe a inicios del siglo XIX. Un análisis demográfico y social a partir del padrón de población de 1816-1817, en Esclavos : una subjetividad negada, M. Ghirardi (Ed.), 1era Edición, Córdoba: Báez Ed. 2019.

${ }^{6}$ En los últimos años, intentando llenar este vacío, realicé algunos trabajos que sirven como antecedente a este artículo: Elías Rodríguez, Ariel Viola y Gisela Zárate, Africanos en Santa Fe en la primera mitad del siglo XIX. El contexto santafesino, participación armada y políticas de emancipación. pp. 552-573. VII Congreso Regional de Historia e Historiografía. FHUC-UNL, Santa Fe, 2017. Disponible en: http://www.fhuc.unl.edu.ar/media/investigacion/publicaciones/HISTORIA/ebook_HISTORIA\%20E\%20HISTO RIOGRAFIA_VII.pdf ; Ariel Viola, Afrodescendientes santafesinos en la revolución. Guerra y libertad. XXV Jornadas de Jóvenes Investigadores de AUGM. Encarnación, Paraguay, octubre 2017; Ariel Viola, Las compañías de pardos y morenos en la Santa Fe revolucionaria. Aproximación a la representación negra en el aparato militar de principios del siglo XIX a través de la revisión de fuentes documentales, en VI Jornadas de Estudios Afrolatinoamericanos, GEALA, septiembre 2019; Ariel Viola, Movilización militar en Santa Fe, de los últimos años coloniales a los primeros años revolucionarios. Aproximación numérica y documental al nivel de militarización, en XVII Jornadas Interescuelas/Departamentos de Historia, UNCA, octubre 2019.
} 
espacio tan politizado como el Litoral rioplatense donde, a partir de 1810, se entrecruzaron modelos revolucionarios, los cuales se enfrentaron en juntas de gobierno, en congresos constituyentes o en campos de batalla. En este sentido, la jurisdicción de Santa Fe es vista como un punto intermedio por donde cruzaban redes, horizontales y verticales, construidas en torno a la experiencia miliciana que los reclutamientos masivos habían habilitado. Por estos canales transitaban opciones políticas que eran debatidas e interpretadas entre los reclutados en cuerpos segregados de pardos y morenos, provenientes de diferentes puntos - Buenos Aires, Montevideo, el Cabildo de Santa Fe- y que dieron motivo a la creación de partidismos y reivindicaciones al interior de la tropa.

$\mathrm{El}$ artículo intenta nutrir este campo de estudios inspeccionando fuentes del Archivo General de la Provincia de Santa Fe: nombramientos civiles y militares entre 1810 y $1813^{7}$, listas de revista de la Compañía de Pardos y Morenos Auxiliares al Ejército del Perú de 1813 en Santa Fe, ${ }^{8}$ el padrón de la ciudad de 1816 y 1817, ${ }^{9}$ el censo de varones de $1823,{ }^{10}$ así como diferentes actas del Cabildo de la década de 1810. Estos acervos son imprescindibles para trazar el recorrido histórico de las unidades de pardos y morenos santafesinas y, a la vez, para rastrear a los soldados negros en otros registros, posibilitando la recreación de algunas trayectorias, a lo que se suma la consulta de actas de bautismo, matrimonio y defunción ${ }^{11}$. Por otro lado, se revisa un sumario militar de 1813 que comprometió a la compañía de pardos y morenos de Santa $\mathrm{Fe}$, destacada en Punta Gorda ${ }^{12}$ y otros documentos del Archivo General de la Nación (Argentina), como también ciertos tomos del Archivo Artigas. ${ }^{13}$

El objetivo principal consiste en la reconstrucción del devenir de las compañías de pardos y morenos de Santa Fe a partir de 1810, con atención particular a su conformación, sus características y la importancia política de esta movilización militar para los negros santafesinos. En el segundo apartado se inspecciona la forma que tomó el reclutamiento de africanos y afrodescendientes en Santa Fe, los rescates militares de

\footnotetext{
7 Archivo General de la Provincia de Santa Fe (en adelante AGPSF), Contaduría, T. 14, L. 1, "Libro de nombramientos de Oficiales y Empleados por Decretos Reales", Año1813, ff. 120-143.

${ }^{8}$ AGPSF, Contaduría, T. 16, L. 16, ff. 272-306, 313-326, 329-341, 349, 352-367.

${ }^{9}$ AGPSF, Gobierno, T. 1 (1573-1830), L. 8, "Padrón del cuartel n 2", ff. 170-185, y L. 9, "Padrón del cuartel n4", ff. 186-210; Cabildo, Documentos Varios, T. 35, "Padrón del cuartel n³”, ff. 1-139.

${ }^{10}$ AGPSF, Gobierno, T. 1, L. 15, ff. 233-243.

${ }^{11}$ Disponibles en https://www.familysearch.org/es/

${ }^{12}$ Archivo General de la Nación (Argentina) (en adelante AGN-A), Sala X, L. 30-2-2, Sumarios Militares, 725.

${ }^{13}$ Comisión Nacional Archivo Artigas (en adelante AA). Disponible en http://bibliotecadigital.bibna.gub.uy
} 
esclavos y el surgimiento y evolución de las unidades militares segregadas. A continuación, se procura hacer un cálculo aproximado del nivel de movilización militar de africanos y afrodescendientes de Santa Fe en los primeros años de la revolución en el Río de la Plata. Por último, se intenta captar la politización miliciana atravesada por las pujas partidarias de la revolución, conectadas con el centralismo porteño y la influencia dentro del Litoral del federalismo de Artigas. En ese sentido, se analizan dos episodios particulares: la circulación de un memorial entre la tropa y la plana menor de la oficialidad del cuerpo auxiliar al Perú en 1813 y el acuartelamiento de la compañía cívica de pardos libres contra el ejército invasor de Viamonte en 1815.

\section{Movilización militar de pardos y morenos de Santa Fe}

La incorporación de Santa Fe en el proyecto revolucionario porteño no fue fácil, de hecho, provocó una gran desorganización del sistema militar ${ }^{14}$. El proceso de revolución y guerra que se abría afectaba a la estructura defensiva santafesina, imponiéndose la Junta revolucionaria sobre la dirección militar de los recursos bélicos. Las compañías se reorganizaban bajo la jerarquía de la Comandancia de Buenos Aires postergando los intereses locales sobre la defensa militar de la ciudad y la campaña. La permanente desarticulación de las milicias rurales había vuelto dificultoso cubrir con el reclutamiento local aquellos lugares militarmente abandonados, teniendo que cubrirse las faltas con los escasos efectivos de la milicia urbana. En 1810, las autoridades de mayo dispusieron la creación de "milicias cívicas" en la ciudad para imponer la causa revolucionaria y, a la vez, intentaron subordinar a las formaciones rurales que se habían formado autónomamente. (Fradkin B 234). Estos hechos implicaron una movilización y militarización más contundente sobre una mayor fracción se los habitantes de la ciudad.

En agosto de 1810, en Santa Fe se instala un nuevo plantel militar que se puede describir a través de la consulta de los nombramientos militares decretados por la Junta Superior Gubernativa entre 1810 y los primeros meses de 1813. También, el índice del Archivo del gobierno de Buenos Aires en 1810 contiene referencias sobre las unidades militares santafesinas 15: dos compañías de Blandengues veteranas -con 200

\footnotetext{
${ }^{14}$ AGPSF, Actas Recuperadas, Caja 1, Acuerdos de 1810, fs. 30-34.

${ }^{15}$ Manuel Trelles, Índice del Archivo del Gobierno de Buenos Aires correspondiente al año de 1810, Buenos Aires, La Tribuna, 1860, pp. 67-77.
} 
plazas reglamentadas-, tres compañías del Escuadrón de Voluntarios de Caballería donde al menos la primera compañía contaba con 60 plazas en una revista de julio de 1810-,16 tres compañías de milicias urbanas, entre las cuales se cuenta la de "Nobles Patriotas Urbanos" de Infantería de la ciudad -con 86 plazas- y una compañía de Pardos Libres -con 100 plazas disponibles-, así como el regimiento de caballería de la Milicia Patricia de Entre Ríos -que en 1812 se dividía en las dos compañías de milicias de Paraná- y el regimiento de caballería de la Villa de Concepción del Uruguay. A Manuel Ruiz, que había oficiado como jefe del batallón de castas que se formó durante las invasiones inglesas, se lo asume como Coronel del Ejército en Santa Fe, aclarando que el cuerpo que conducía era elevado a regimiento, "este y los demás cuerpos de su clase", ${ }^{17}$ y al mismo tiempo, la Junta Superior Gubernativa de Buenos Aires lo declara como Teniente de Gobernador de la jurisdicción.

La compañía de Pardos libres era un cuerpo cívico de infantería, de "nueva creación" ${ }^{18}$ organizado para resistir el posible ataque realista desde Montevideo, y contaba con una fuerza estimada en unos 100 hombres (Gianello 180). En el registro del 10 de octubre de 1810, en que se nombra a Miguel Corbera “...por la necesidad que ay de nombrar un Ayudante Mayor que instruya la Compañía de Pardos...", ${ }^{19}$ se atendía a una recomendación de adiestramiento de la tropa que no se aclaraba para el resto de los cuerpos. En diciembre, el Teniente de Gobernador consultaba a la Junta sobre el prest que debía pagarle a los soldados pardos, ${ }^{20}$ cuestión que aparentemente no se resolvía de la misma forma que con el resto de los reclutas por tener una condición racial discriminada dentro del sistema de castas que continuaba vigente.

Los cuerpos militares de castas eran segregados de los compuestos por españoles o vecinos de la elite, sin embargo, la plana mayor de su oficialidad, en su mayoría, era blanca, porque el estigma de su condición étnica construía una representación de incapacidad para que se capitaneen a ellos mismos. Aunque esta cuestión es interpelada por Andrews cuando comprueba que en las compañías de afroporteños muchos oficiales, de la plana menor más que la mayor, eran pardos y

\footnotetext{
${ }^{16}$ AGPSF, Contaduría, T. 15, L. 13, "Milicias de la Provincia-Planilla de sueldos", ff. 1045-1045v.

17 AGPSF, Contaduría, T. 14, L. 1, "Libro de nombramientos de oficiales...", f. 120.

${ }^{18}$ AGPSF, Contaduría, T. 14, L. 1, "Libro de nombramientos de oficiales...”, ff. 128v-129

${ }^{19}$ AGPSF, Contaduría, T. 14, L. 1, "Libro de nombramientos de oficiales...", ff. 123-123v

${ }^{20}$ Sueldo que se asignaba a las plazas de cada cuerpo militar. En Santa Fe, desde fines del siglo XVIII, muchos soldados habían abandonado la milicia por el adeudamiento del prest, a veces, por más de una año.
} 
morenos, incluso algunos ascendían socialmente dentro de las legiones, mutando a la categoría étnica de "trigueño" (Andrews 143). Bartolomé Cámara, por ejemplo, en el registro bautismal de sus hijos, figura como "pardo libre", logrando alcanzar el puesto de capitán de la milicia de pardos de Santa Fe en 1813 (Candioti B 150). La discriminación instituida justificaba la organización separada de los soldados negros y mestizos, no así para los indígenas reclutados, como se percibe en el decreto que la Junta expidió en junio de 1810, antes de que se formasen las unidades negras en Santa Fe. ${ }^{21}$ Esa misma diferenciación operaba en el hecho de que los afrosoldados sólo servían en la artillería y en la infantería, no en la caballería, que estaba reservada a los vecinos mejor acomodados. (Goldberg 43).

En 1813 la milicia cívica de Pardos libres fue transformada en regimiento debido a las modificaciones que ocasionó la llegada del Barón Holmberg a Santa Fe (Fradkin B 245). Enviado desde Buenos Aires a fines de 1812, portaba una autorización para que todas las tropas santafesinas quedasen bajo su mando, asignando oficiales veteranos a los milicianos. Durante los primeros años revolucionarios las milicias estuvieron en permanente movilización, característica que era propia de los cuerpos veteranos regulares, pero no estaban acuarteladas y seguían siendo oficiadas por hombres "cívicos" reclutados, y no por una plana mayor veterana, como la que se le imponía en esta ocasión, por su conversión en regimiento. Dichos cambios pudieron haber supuesto un aumento en el número de negros levados.

La movilización de negros y mestizos también se incrementó en 1813 por los "rescates" militares, instrumento del que se sirvió el Estado para aumentar el reclutamiento de hombres en las armas. De esta manera, los libertos pasaban a formar parte de las compañías segregadas que servían en el ejército independentista. A principios de 1814 fueron rescatados 9 esclavos libertos de "la ciudad de Santa Fe y su Distrito", 22 que fueron enviados a Buenos Aires para ser agregados en el Séptimo y Octavo Batallón de Infantería. Candioti afirma “...que la incorporación en el ejército

\footnotetext{
${ }^{21}$ Registro Oficial de la República Argentina, t. I (1810-1821), Buenos Aires, Imprenta de la República, 1879, p. 34. Citado en Magdalena Candioti, Altaneros Y libertinos. Transformaciones de la condición jurídica de los afroporteños en la Buenos Aires revolucionaria (1810-1820). Desarrollo Económico, Vol. 50, Nro. 198, 2010, págs. 271-296.

22 Archivo General de la Nación (en adelante AGN), Sala X, 43-6-9, Rescates de esclavos 1813-1817, "Relación de los esclavos libertos que han tocado a la ciudad de Santa Fe y su distrito". Los rescatados son: Juan Candioti, Lorenzo Candioti, Elías de Santo Domingo, Felipe Carrizo, Manuel del Convento de la Merced, Bartolo Ramírez, Pedro Braga, Pedro Navarro, Cayetano de la Puente.
} 
constituyó una vía importante por la que muchos africanos y afrodescendientes esclavizados accedieron a su libertad, e incluso pudieron ascender socialmente" (A 115). En el padrón de 1823 -en el que sólo fueron anotados los varones del tercero de los cuatro cuarteles de la ciudad-se observan 11 soldados pardos y morenos libres que pueden haber sido rescatados por el gobierno revolucionario, además de los 9 de 1814 recién mencionados. 23

Bajo estas circunstancias, en 1813 se levantó la Compañía de Pardos y Morenos Auxiliares al Ejército del Perú, destacada en Punta Gorda, de la que contamos con listas de revista en el AGPSF. En ellas se pueden enumerar 101 plazas, 80 soldados más 21 oficiales -3 de la plana mayor y 18 de la menor-, aunque su composición fue variando en el transcurso de 1813 ante las altas y bajas de efectivos.

La condición de regimiento corrió durante 1814 para los pardos libres enrolados en la milicia urbana, produciendo una ampliación del reclutamiento para este cuerpo, llegando a contar con más de 900 plazas (Fradkin B 244). Los regimientos eran fuerzas de infantería y, según los criterios de la organización militar de la revolución, estaban formados por dos batallones de 600 hombres cada uno (Rabinovich B 22). Para ese mismo año, además del de pardos, Fradkin cuenta 400 soldados para otro regimiento, el de Granaderos de Infantería, y también 149 efectivos del Escuadrón de Caballería. Sin contar las milicias de campaña, la militarización alcanza a unos 1449 efectivos, más del 10\% de la población de la jurisdicción, y aproximadamente el 20\% de los vecinos de la ciudad, "es decir, un nivel de movilización equivalente o incluso superior al de Buenos Aires" (Fradkin B 244).

\section{Primera aproximación al nivel de movilización de soldados pardos y morenos en la Santa Fe de la revolución.}

Se hace indispensable intentar acercarse provisoriamente a la cantidad de africanos y afrodescendientes de Santa Fe que, a partir del proceso de militarización que implicó el estallido revolucionario y el inicio de las guerras de independencia, fueron reclutados para conformar las unidades segregadas. Para ello, se intenta poner en práctica un ejercicio para calcular el nivel de movilización, es decir, las cantidades de pardos y morenos santafesinos que fueron reclutados en las dos compañías que se

\footnotetext{
${ }^{23}$ AGPSF, Archivo de Gobierno, T. 1, L. 15, ff. 233-243.
} 
organizaron en la jurisdicción: la cívica de pardos libres, creada en 1810 y devenida en regimiento en 1813, y la de pardos y morenos auxiliar al Ejército del Perú, destacada en la batería de Punta Gorda ese mismo año. Las cifras obtenidas resultan del cruce de los datos disponibles en las listas de revistas de 1813 -con el fin de observar el grado de representación de los soldados negros entre los reclutados de todas las fuerzas- con los del padrón urbano realizado a fines de 1816 y principios de 1817 -para captar la importancia demográfica del reclutamiento en la población de Santa Fe.

Los "pie de lista de los individuos que tiene dicha compañía para la revista del Comisario" eran registros que se levantaban mensualmente, donde se anotaba el nombre y apellido de los presentes para que la administración de hacienda destine los sueldos y otros pertrechos. En las mismas no se hallaba información sobre la edad, la clase, la etnia o el estado civil de los soldados, sólo sabemos que eran varones mayores entre 15 y 60 años (Goldberg 42). También, a través de las listas se puede observar quienes integraban la plana mayor -capitanes, tenientes, subtenientes, alférez- y quienes la menor -sargentos, cabos, tambores y pitos. ${ }^{24}$ El resto de la fuerza es apuntada simplemente como "soldados", en algunas ocasiones se agregan, junto a los nombres, la etiqueta de "distinguido". Por último, este documento da cuenta de las bajas y las altas que han tenido lugar en el mes consignado, pudiéndose conocer las deserciones, las muertes o las incorporaciones de efectivos mes a mes.

Las listas de revista existentes en el archivo cuentan con algunos problemas para obtener un resultado sistemático. En primer lugar, no se cuenta con un orden cronológico continuo para todas las unidades militares, impidiendo que se puedan hacer series absolutas para el total de las fuerzas. En este sentido, no se conocen las revistas de la milicia cívica de pardos libres, pero se sabe de su composición por otras fuentes y el trabajo de otros autores. Sólo podemos hacer un cálculo representativo entre febrero y octubre de 1813, año para el cual se cuenta con listas de todas las compañías de Santa Fe, entre éstas, la de pardos y morenos auxiliares al Perú. Sólo se contabilizan -dentro de esta aproximación - a aquellos a los que la fuente considera que ocupan plazas dentro de cada compañía, es decir, los soldados y la oficialidad de menor rango, quienes, en conjunto, se denominan "tropa" (Rabinovich B).

\footnotetext{
${ }^{24}$ Ver Alejandro Rabinovich, Ser soldado en las Guerras de Independencia. La experiencia cotidiana de la tropa en el Río de la Plata, 1810-1824, Buenos Aires: Sudamericana. 2013.
} 
Observando particularmente los datos para la Compañía de Pardos y Morenos Auxiliares al Ejército del Perú, destacada en Punta Gorda durante 1813, se verifica un total de 105 movilizados entre febrero y septiembre de 1813, 21 oficiales y 84 soldados. Entre estos, se cuentan 21 desertores y sólo 4 incorporados en los ocho meses. Si se los compara dentro del cuadro de reclutamientos de todas las compañías de Santa Fe para ese año se evidencia que los pardos y morenos constituían casi la tercera parte, un porcentaje importante del total de los movilizados:

Cuadro 1. Cantidad de reclutados en las compañías de Santa Fe en 1813.

\begin{tabular}{|l|c|c|c|c|c|c|}
\hline \multicolumn{1}{|c|}{ Unidades militares } & Oficiales mayores & \multicolumn{2}{c|}{ Tropa } & \multicolumn{2}{c|}{ Total } \\
\hline BLANDENGUES DE SANTA FE & 4 & $16,00 \%$ & 95 & $13,79 \%$ & 99 & $13,86 \%$ \\
\hline $\begin{array}{l}\text { REGIMIENTO DE PATRICIOS } \\
\text { DE LA PATRIA - 7 }{ }^{\circ} \text { Comp. }\end{array}$ & 6 & $24,00 \%$ & 133 & $19,31 \%$ & 139 & $19,47 \%$ \\
\hline $\begin{array}{l}\text { PIQUETE DE ARTILLERÍA } \\
\text { DE LA PATRIA }\end{array}$ & 7 & $28,00 \%$ & 113 & $16,40 \%$ & 120 & $16,81 \%$ \\
\hline $\begin{array}{l}\text { COMPAÑ́́A DE PARDOS Y } \\
\text { MORENOS AUX. AL EJ. DEL PERÚ }\end{array}$ & 3 & $12,00 \%$ & 102 & $14,80 \%$ & 105 & $14,71 \%$ \\
\hline $\begin{array}{l}\text { MILICIA CÍVICA } \\
\text { DE PARDOS LIBRES }\end{array}$ & 1 & $4,00 \%$ & 100 & $14,51 \%$ & 101 & $14,15 \%$ \\
\hline $\begin{array}{l}\text { ESCUADRÓN VOLUNTARIOS } \\
\text { DE CABALLERÍA }\end{array}$ & 2 & $8,00 \%$ & 60 & $8,71 \%$ & 62 & $8,68 \%$ \\
\hline MILICIAS URBANAS & 2 & $8,00 \%$ & 86 & $12,48 \%$ & 88 & $12,32 \%$ \\
\hline TOTAL & 25 & $100 \%$ & 689 & $100 \%$ & 714 & $100 \%$ \\
\hline
\end{tabular}

Elaboración propia en base a: AGPSF, Contaduría, T. 16, L. 16, ff. 272-306, 313-326, 329341, 349, 352-367; Manuel Trelles, "Índice del Archivo del Gobierno de Buenos Aires correspondiente al año de 1810”, Buenos Aires, La Tribuna, 1860, pp. 67-77.

En la muestra poblacional - de tres cuarteles sobre cuatro- que se puede extraer del padrón levantado entre diciembre de 1816 y enero de 1817, se contabilizan 5.639 habitantes en Santa Fe, 3.111 mujeres y 2.528 varones. ${ }^{25}$ De estos últimos, la cantidad pasible de ser reclutada, los adultos entre 15 y 60 años, se calcula en 1309, el 23,21\% de los habitantes de la ciudad. El total de 689 reclutados para las tropas representa el $52,63 \%$ de éstos.

De los 202 movilizados pardos y morenos que suman la milicia cívica local y la compañía regular auxiliar al frente altoperuano, significan un 29,31\% en el conjunto de las compañías, y un 15,43\% de los habitantes con las condiciones etarias para ser alistados. De los 772 varones pardos y morenos que se observan en el padrón, 428 cumplen los requisitos para ser alistados en las compañías, el 23,88\% de los africanos

\footnotetext{
${ }^{25}$ Un análisis detallado en Magdalena Candioti et al (2017). Esclavos, libres y libertos en la ciudad de Santa Fe a inicios del siglo XIX. Un análisis demográfico y social a partir del padrón de población de 1816-1817. En Esclavos, una subjetividad negada. M. Ghirardi (Ed.). 1era Edición, Córdoba, Báez Ediciones, 2019.
} 
y afrodescendientes registrados en la ciudad y el 32,69\% de la población que puede reclutarse. A partir de los datos, se puede llegar a una estimación de la importancia de la militarización para la población negra y mestiza de Santa Fe en 1813: el 47,19\% de los adultos varones pasibles de ser reclutados -que coincide con la edad activa laboralmente- y el 11,27\% de todos los pardos, morenos y negros de la ciudad.

\section{Politización miliciana de pardos y morenos en el Litoral rioplatense.}

Pertenecer a la milicia significaba, en múltiples sentidos, formar parte de uno de los órganos del Estado por donde se canalizaban el poder y la toma de decisiones, cuestiones tradicionalmente reservadas para los vecinos ilustres de la ciudad, es decir, propietarios blancos. En Buenos Aires, los grupos de castas ya venían siendo incorporados en cuerpos segregados desde los últimos años de la colonia pero, en Santa $\mathrm{Fe}$, los negros libres recién fueron levados en compañías locales ante las necesidades de la guerra que surgieron a partir de 1810. Distinta fue la situación para los esclavos que fueron rescatados por el Estado, quienes fueron enviados fuera de Santa Fe a engrosar los regimientos de línea. Para éstos, incluso, los cambios suscitaron una vinculación diferente con las autoridades, como bien señala Mariano Aramburo, más aún si tenemos en cuenta que no se había recurrido a su movilización antes de que estallara la revolución.

El reclutamiento extendido que ponía en práctica el Estado revolucionario ante la coyuntura apremiante, inauguraba un contacto más directo entre las autoridades y los sectores populares, un compromiso de la revolución con el pueblo llamado en armas. (Di Meglio A 45). Hombres de diversa procedencia fueron agrupados en tropas para actuar como efectivos, estableciéndose un surtido de situaciones de fuero y salario.

...había voluntarios "enganchados" a cambio de un sueldo, esclavos "rescatados" confiscados a sus amos y que obtendrían su libertad al término de su servicio y también “destinados", es decir, perseguidos por la justicia acusados de "vagancia" y cuya pena era el llamado "servicio de las armas". Se trataba, por tanto, de soldados reclutados entre los sectores más bajos de la sociedad y tenían muy diversos orígenes tanto que los sujetos que caían bajo las levas eran en su mayor parte varones jóvenes que se desempeñaban como peones y que solían ser migrantes. (Fradkin y Ratto 4). 
La experiencia militar acercaba los soldados entre sí, habilitando lazos horizontales. Para los negros, formar parte de los cuerpos implicaba identificarse con las distintas comunidades locales del Litoral, ya que éstas eran reunidas dentro de las compañías y, muchas veces, desplazadas hacia otros territorios, poniéndose en juego vínculos de carácter regional mediante los cuales los afrodescendientes compartían realidades socio étnicas de un mismo sistema, el cual los implicaba a cada uno dentro de un conjunto. Las redes tramadas por líderes negros dentro de los cuerpos segregados cruzaban la cuenca del Plata, mientras que sus raíces partían de múltiples escenarios diseminados en el territorio -Buenos Aires, Santa Fe, Montevideo-, desde donde los sujetos actuaban activando enlaces institucionales que facilitaban desplazamientos, cambios de bando o tomas de partido. (Borucki 114-115). La Banda Oriental, como uno de los puntos conectados con Santa Fe dentro de la red de militarización, puede constituir un reflejo de la situación de ésta:

En Montevideo, las tropas negras tuvieron un papel significativo en los ejércitos, así como fue decisiva la participación negra en facciones rivales para el resultado de disputas políticas mayores. Si bien las fuentes no revelan una "política negra" de los soldados (...) es claro que el accionar de los soldados negros no se limitó a seguir y obedecer a los actores más importantes, los caudillos rioplatenses, sino que ellos perseguían sus propios intereses (incluso a veces poniéndose en contra de los jefes de tropa de color blanco). (Borucki 149).

Es esencial el hecho de que el dinamismo de estas redes constituía un importante móvil político para los soldados negros. Beatriz Bragoni, en su trabajo sobre la militarización popular en Cuyo, es precisa al afirmar que "esa maquinaria estructurada por lazos personales como de vecindad (...) por las relaciones cara a cara, y robustecidas por la circulación de pasquines o proclamas, parece haber sido eficaz para difundir las pretensiones políticas de los negros superando los cuarteles urbanos, y penetrando en la campaña circundante". (119). Por otro lado, las formas de movilización y las acciones coordinadas dentro de las tropas manifestaban una cultura política plebeya articulada en los diferentes idearios revolucionarios, donde "la negociación y la violencia política ingresaban de esta manera en la resolución de conflictos sociales potenciados por la revolución y la guerra". (Mata 132).

Antes de examinar los casos que se exponen a continuación, se hace necesario advertir que cada uno de ellos se imprime en diferentes momentos de la vertiginosa década revolucionaria. El primero sucedió en 1813, cuando el centralismo porteño 
todavía era muy fuerte para la dirección revolucionaria y militar de Santa $\mathrm{Fe}$, preparando sus tropas para enfrentar a las fuerzas realistas que estaban entrando por los Entre Ríos. En cambio, el segundo ocurrió a fines de 1815, cuando Santa Fe luchaba por afirmar la autonomía provincial que había declarado en abril, resistiendo la intervención porteña del Ejército de Observación comandado por Viamonte, a la vez que era tutelado por la Liga de los Pueblos Libres de Artigas.

\section{El memorial de la Compañía de Pardos y Morenos Auxiliares al Perú destacada en Punta Gorda, 1813. La red miliciana del Capitán Riverola.}

El rearme y desarme de las baterías y la configuración de nuevos cuerpos militares se volvieron moneda corriente. Desde que la Banda Oriental comenzó a resistir la sujeción a Buenos Aires la ciudad de Santa Fe se convirtió en un foco de ataque y retaguardia, preparándose, en 1812, un conjunto de tropas con destino a combatir el avance realista de Elío. A fines de ese mismo año llegó desde la capital un nuevo teniente gobernador militar, el Coronel Beruti, junto con el Barón Holmberg, y crearon una batería en Punta Gorda para contener la escuadrilla española que estaba llegando a la frontera sur. Los hechos fueron percibidos igual que antes, como una intromisión desafortunada, afectando nuevamente al plan estratégico de la ciudad.

La compañía negra auxiliar al frente altoperuano que se formó en Santa Fe en 1813 protagonizó una manifestación en la batería de Punta Gorda, donde actuaba como guarnición costera desde principios de ese año. Di Meglio relata el suceso, donde se establecen lealtades, traiciones y acusaciones entre los mismos miembros del cuerpo. Aquí también se exponen algunas reflexiones que suscitaron la consulta de ese mismo sumario militar, el cual testimonia el juicio que provocó el accionar de esta compañía.

El sumario se levanta el 6 de octubre "A consecuencia de las Conmbulciones acontesidas en esta, en los días 28, 29, y 30, del que espido, con la Compañía de Pardos y Morenos Auxiliar del Perú", donde se acusa "haver sido Cavezas y seductores los sargentos de la misma Basilio Pino de 1ra Clase, y Juan Fastin de 2da”, y se ordena "hoy mismo sin pérdida de tiempo, a poner presos a estos, incomunicados con una barra de grillos, y a tomar las correspondientes informaciones contra ellos" ${ }^{26}$

\footnotetext{
${ }^{26}$ AGN-A, X, 30-2-2, Sumarios Militares, 725, f. 1.
} 
El capitán, Mariano Riverola, había marchado a Buenos Aires para buscar sueldos y vestuario, ausentándose desde abril de 1813 según lo observado en las listas de revista. Cuando regresó, pocos días antes de lo ocurrido, detenido desde su casa, mandó a miembros de su tropa a solicitar al comandante la autorización para ir rápidamente a Santa Fe porque le habían robado los pertrechos asignados. El superior tomó el hecho como un descuido del capitán y lo hizo apresar. En seguida, uno de los sargentos, Juan Fastin, puso en circulación un memorial en el que se pedía la liberación de Riverola y el permiso de partida a Santa Fe para recuperar algo de lo sustraído. Entre los firmantes de la demanda figuraban: los sargentos Basilio Pino y Juan Fastin, y los cabos Mateo Rodríguez, Pedro Díaz, Pedro Adarme, Domingo Rodríguez y Juan Vilar. Este último, en su interrogatorio, declara “...el Sargento de primera Clase Bacilio Pino, handava diciendoles a los compañeros que era presizo que todos firmasemos el Memorial para presentarlo al Señor Comandante para que fuese nuestro Capitan con una Custodia nuestra a Santa Fe a traer el Dinero, que tenía una libranza para Don Francisco Candioti de quinientos pesos...". ${ }^{27}$ Es decir, los líderes de la demanda eran, principalmente, el sargento primero y el Capitán, afrodescendientes libres originarios de la capital revolucionaria, ${ }^{28}$ y estaban activando lazos provenientes de Buenos Aires -las asignaciones dadas a Riverola-, como de Santa Fe -la libranza de 500 pesos que debía llevarle a Francisco Candioti -líder capitular de las aspiraciones autonomistas locales-y, por debajo, desde Montevideo llegaba la influencia de José Gervasio Artigas, como veremos enseguida.

Más adelante, Vilar incluye a un soldado de la tropa, Antonio Sosa:

era menester que cargasemos las Armas y sacasemos las Municiones de la Casa del Alferez Don Santos García, y que era menester dar contra el Comandante de este Punto y contra todos los que no eran de nuestro Partido y el dicho Sosa agitaba mas que era menester poner una Sentinela de los nuestros en la Puerta de la Casa de nuestro Capitan (...) y desia el Sargento Fastin que era menester que todos estuviesemos listos y sobre las Armas por lo que podia acontecer con nuestro Capitan y según lo que dice el declarante que en la Casa del Capitán que se reunieron todos para hacer el Memorial y que fue hecho por un soldado que trajo el Capitan de la Capital que aun no esta filiado y no es soldado de la Compañia y

\footnotetext{
${ }^{27}$ Idem, f. 8.

${ }^{28}$ En los bautismos de sus hijos figuran como pardos libres. En el acta de 1811, Pino figura como negro libre esposo de una esclava, Gabriela. FamilySearch.com, Ciudad de Buenos Aires, Nuestra Señora de La Merced, Bautismos 1809-1816 (mestizos, mulatos y negros), imagen 113. El capitán Riverola era pardo libre, como su esposa, según se consta en acta de 1819. FamilySearch.com, Ciudad de Buenos Aires, Nuestra Señora de La Merced, Bautismos 1817-1853 (mestizos, mulatos y negros), imagen 121.
} 
que es el que ha puesto todas las firmas porque los mas Sargentos y Cavos no saven escribir ni aun les han tomado parecer. ${ }^{29}$

En primer lugar, la apelación a un "partido" revela el proceso de politización militar que estaban atravesando los soldados afrodescendientes de Santa Fe y el nivel de violencia que podía conllevar quitar las municiones de la casa del alférez o "dar contra el Comandante de este Punto". En segundo lugar, es interesante advertir que la agitación partía de parte de los oficiales, pero también se la hacía circular entre los soldados, y que, dentro de la oficialidad, las acusaciones iban de un cabo (Vilar) a un miembro de mayor rango (el sargento primero, presumiblemente Pino), como también a un subordinado (Sosa), que se lo expone como un gran agitador. En tercer lugar, pueden hallarse evidencias de un cierto grado de organización: "poner una Sentinela de los nuestros", apelándose a una identificación grupal, o "era menester que todos estubiesemos listos y sobre las Armas por lo que podia acontecer con nuestro Capitan”. Por otro lado, el interrogado expuso que el memorial fue escrito por un soldado extraño de la capital, Lisandro Amable, que había puesto las firmas en nombre de los suboficiales analfabetos, entrando otro miembro de la red de relaciones de Riverola en Buenos Aires.

La declaración continúa destacando que el sargento Fastín advirtió a los que desertasen bajo la amenaza de las armas y que conspiró trasladarse a Coronda y pedir caballos al comandante con un papel falso, contando con la posibilidad de obligarlo por la fuerza ante la negativa de éste. $3^{\circ}$ Ese era el pretendido plan por el que el fiscal preguntaba a los nueve testigos. Todos negaban haber formado parte de él, jugándose traiciones, lealtades y delaciones en el paño. El desconocido Amable, reconoce que tanto las firmas como el memorial era de su propio puño pero, quizá para salvarse debido a que no tenía afinidades con los otros soldados, delató la coartada del capitán y a los otros líderes, advirtiéndose el tráfico de influencias:

el Sargento Primero Bacilio Pino handaba ceduciendo a todos para que rubricasen los Nombres y Apellidos (...) que se salia afuera de la Casa del Capitan y quedaban conversando (...) el Sargento Primero y el Sargento Fastin y barios Cavos y soldados que como el declarante no los conocía no sabe decir como se llaman: pero si al que conoce es al soldado Antonio Zosa, y que el capitán les prometió el pagarles en término de tres meses el dinero

\footnotetext{
${ }^{29}$ Ibidem, f. 8-9.

${ }^{30}$ Idem, f. 9.
} 
que el tenia quien le diese dinero en Santa Fe (...) que dicho Capitan le prometió hacerlo Gente porque le dijo que tenia Tienda de Comercio: o si no lo acomodaría en la Compañía (...) que era mejor que centase Plaza que en la carrera militar lo pasaría grandemente. ${ }^{31}$

Como se apuntó anteriormente, y como lo estaría ratificando el Capitán Riverola, las unidades militares eran un ámbito propicio para alcanzar una movilidad social ascendente, y los recursos de los que se valía este, por ser el oficial de mayor rango, se ponían a disposición para hacer funcionar redes sociales milicianas y para comprar voluntades que permitiesen alcanzar los intereses perseguidos o hacer triunfar un movimiento insurreccional. Tanto Pino y Fastin como Sosa y Amable -que a partir del sumario sabemos que son pardos de no más de 36 años- se acusaron entre ellos. Incluso, en la confesión del primero se percibe que el capitán destacaba que en Santa Fe, además de Candioti, lo esperaba para ayudarlo Juan Antonio Pereira, quien había sido teniente gobernador de Santa Fe el año anterior. ${ }^{32}$

En la misma testificación del sargento Basilio Pino aparece otro punto de la red del Capitán Riverola, el bando de Artigas:

"a eso de las tres o las cuatro de la tarde recibio un papel el declarante de su Capitan diciendole que tuviese mucho cuidado en su Guardia porque el Señor Comandante yba a ponerlos presos a todos los sargentos y cavos y despacharlos a Buenos Ayres (...) y a eso de las siete de la noche manda (...) al Pardo que trajo de la Capital Lisandro Amable (...) y que decia el Capitan que ya tenia algunos hablados para que nos fuesemos al Ejército a honde estaba el General Artigas”.33

La incertidumbre de los protagonistas del pronunciamiento terminó por neutralizarlo: todos habían desmentido haber firmado el memorial amparados bajo su condición de analfabetos, acusando que sus nombres habían sido colocados por otro. El resultado judicial del motín fue el encarcelamiento sólo del capitán, acusado de instigar a varios a pasarse junto a él "al Exercito honde estaba el General Artigas". La última lista de revista de la compañía es la de aquel octubre de 1813, cuando daban de baja a Riverola quedando acéfalo el cuerpo. Fechada el 5 de octubre, junto a la

\footnotetext{
${ }^{31}$ Idem, f. 14-15.

${ }^{32}$ Idem, f. 20.

${ }^{33}$ Idem, f. 21.
} 
anotación de "presente" del capitán, se agrega: "regresa preso de la Capital desde el 29 de septiembre". 34

Más allá de las vicisitudes, el motín consistió en una acción colectiva proveniente de los soldados negros, demostrado tanto solidaridades como traiciones entre ellos. Además, el motivo por el que Riverola quedaba bajo prisión responde al asunto político y militar que marcaba a fuego a Santa Fe y que mantenía celoso al centralismo porteño: su cercanía e influencia con la otra facción de la revolución, el movimiento artiguista.

\section{El acuartelamiento de la milicia cívica de Pardos Libres de Santa Fe, 1815.}

\section{Las influencias de Viamonte y la resistencia de los soldados negros.}

Entre 1810 y 1815 Santa Fe vivió con poco ánimo la imposición de tenientes de gobernador nombrados por Buenos Aires, dirigente único de la revolución durante ese período. Desde los primeros e intensos años de la revolución, la ciudad fue construyendo una tendencia autonomista que se fundaba en la reticencia hacia el control por parte de autoridades militares ajenas. Éstas chocaban con los intereses del Cabildo respecto al refuerzo de las fronteras y la sujeción a la causa revolucionaria, manipulada por el centralismo porteño, y la extracción de recursos que esto implicaba.

El alejamiento del centralismo porteño se volvió una alternativa real en 1814, cuando se extendía la causa de Artigas por el Litoral y las tropas autonomistas orientales se instalaban en Entre Ríos. Gianello destaca la exacerbación del movimiento autonomista cuando Entre Ríos fue erigida en provincia por una medida del Director Don Gervasio de Posadas. (195). La frontera, esta vez en La Bajada del Paraná, era otra vez un asunto problemático, pero el conflicto principal se daba por las intervenciones de los ejércitos de Buenos Aires contra las tropas de Artigas. Las milicias locales empezaban a verse atraídas por la causa de este caudillo. El viraje hacia la causa federal de Artigas fue encausado, además, por el hecho de que desde Buenos Aires se hacía recaer sobre Santa Fe la contención del avance de las fuerzas orientales sobre Entre Ríos, transfiriendo efectivos que custodiaban la frontera, reclutando a los vecinos e inventariando armas y municiones para un plan de defensa.

\footnotetext{
${ }^{34}$ AGPSF, Contaduría, T. 16, L. 16, ff. 352-367.
} 
La rebelión autonomista de Santa Fe se precipitó por la intervención de Artigas tras la derrota conseguida por las fuerzas orientales sobre las porteñas y santafesinas dirigidas por Holmberg. El 26 de abril de 1815, luego de haber expulsado a Eustaquio Díaz Vélez de la tenecia de gobernación, Francisco A. Candioti declaró la autonomía de Santa Fe bajo la protección del jefe oriental. (Gianello 195-196). Cuatro meses después, Buenos Aires formó un Ejército de Observación sobre Santa Fe que se instaló en el límite jurisdiccional: "una cuadrilla de gente armada llegaba a las afueras de la ciudad, y el general Viamonte por tierra con mil quinientos hombres de todas armas, entraba por Santo Tomé el 25 de agosto, en momentos en que fallecía el gobernador Candioti”. (Cervera B 141-142). Así comenzó una guerra interprovincial que se prolongaría hasta 1820, y que repercutió en el enfrentamiento entre dos modelos revolucionarios, el centralista del Directorio y el confederal de Artigas.

En esos tiempos, los estados de fuerza de la ciudad consistían en " 3 compañías de Blandengues, 90 soldados, 17 entre oficiales, sargentos, tambores, cabos; 71 fusiles, otras tantas cartucheras y 10 cartuchos para cada uno y de las auxiliares, 130 plazas entre oficiales, sargentos, cabos y soldados". 35 Las auxiliares referían a la compañía de pardos y morenos que servía para el Ejército del Perú. También, puede constatarse la existencia de más de una compañía de "pardos cívicos", al menos se menciona una segunda unidad, capitaneada por Bartolomé Cámara. $3^{36}$

La politización, ligada a la militarización, llegó a todos los sectores sociales reclutados por el gobierno revolucionario o provincial, tanto en las milicias como en los ejércitos de línea. De hecho, ante la rendición de Díaz Vélez se convocó a los oficiales de las milicias para que cooperen en la elección de la gobernación vacante: "se acordó publicar por bando que todos los vecinos y habitantes alistados en la milicia se presenten a formar parte de las compañías y se pasó orden por el Ayudante de Plaza a todos los capitanes y oficiales de ella para que hagan las listas y se entreguen al Ayuntamiento (...) para la elección de persona que gobierne la provincia”. 37

Ante la convocatoria electoral, expedida desde las autoridades locales a los vecinos y soldados de las milicias, surgen dudas de si "la igualdad, libertad y seguridad

\footnotetext{
${ }^{35}$ AGPSF, Actas Recuperadas Caja 2, Acuerdos de 1815, ff. 22-22v.

36 “Acta de la sesión del Cabildo de Santa Fe...", [Santa Fe, julio 28-27 de 1815], AA, T. XXIX, p. 226.

37 AGPSF, Actas Recuperadas Caja 2, Acuerdos de 1815, ff. 22-22v.
} 
de los ciudadanos y los pueblos" sería extendida a todos los habitantes de Santa Fe, de todos los sectores sociales. ${ }^{38} \mathrm{~A}$ fines de 1815 , ante la elección de representantes para la designación de los capitulares para 1816, el Cabildo trata "sobre la consulta realizada el 12 de noviembre a la Honorable Junta respecto a la duda de si los pardos libres nacidos en este suelo, hijos de esclavos tienen voto activo en la Asamblea electoral". 39 El mes siguiente, la Junta Provincial controlada por el Directorio proscribe a los afrodescendientes de votar bajo el fundamento de una naturaleza vinculada a la esclavitud, argumento que burla la retórica igualitaria y anti-esclavista de los asambleístas del Año 13, se declaraba "que debe regir con respecto a los hijos del país lo mismo que está determinado con concepto a los originarios de Africa”. 40

En septiembre el Directorio había retirado la veteranía a la Compañía de Pardos que estaba "acuartelada con concepto a que fuese veterana", y dictamina que "sea cívica y bajo la inmediata dependencia de este Ayuntamiento, debiendo nombrársele oficiales de su misma naturaleza, proponiendo los españoles que quedaron sin ocupación por los cambios", ${ }^{41}$ los cuales refieren a los reacomodamientos militares que efectuó Viamonte luego de la invasión, colocando oficiales de su ejército como jefe de las milicias locales.

Las autoridades políticas y militares locales eran conscientes del accionar político y la capacidad contestataria de las milicias. El 11 de noviembre de 1815 el Comandante de Armas, José Manuel Troncoso, recomienda al Teniente de Gobernador, Juan Francisco Tarragona, no ejecutar la declinación del cuerpo de pardos de unidad veterana a cívica: “...he creido de mi dever hacer á V. varias reflexiones, y por las que no dudo será combencido lo vtil, preciso y necesario qe es al decoro del Govno, y al bien publico, qe la antedicha Compañía de Pardos continue en clase de Veterana". Este fragmento puede ser interpretado como un llamado a la prudencia, siendo necesario para el bien público evitar que los soldados pardos se subleven. Troncoso describe la movilización militar de los afrodescendientes santafesinos: “...los quatro Oficiales dela Comp. de Pardos abandonaron sus intereses,

\footnotetext{
${ }^{38}$ Instrucciones dadas por el general Artigas a los diputados que envió el Congreso de 1813, en Manuel Cervera, Historia de la Ciudad y Provincia de Santa Fe, 1573-1853, Tomo II, Santa Fe, Librería e Imprenta la Unión. 1908. Apendice, p. 8.

${ }^{39}$ AGPSF, Actas Recuperadas Caja 2, Acuerdos de 1815, ff. 43v - 44v.

${ }^{40}$ Idem, ff. $51-51 \mathrm{v}$.

${ }^{41}$ Idem, ff. $42 \mathrm{v}-43 \mathrm{v}$.
} 
y se prestaron gustosos al servicio de las Armas, lo mismo qe algunos soldados de ella, y otros que por su buena conducta, y circunstancias fueron alistados, hoy estan desempeñando sus deveres con no escasa complacencia...”, por tanto la rebaja de su categoría sería interpretada como un insulto para la oficialidad de la compañía. ${ }^{42}$

El acuartelamiento de la compañía de pardos comenzó en septiembre de 1815 por el retiro de su rango de veterana y por la orden de apartar a sus oficiales cívicos por otros de la plana de Viamonte, y terminó el 14 de diciembre, cuando se le exige "el inmediato desacuartelamiento mandando hacerles entender genialmente las obligaciones a que están contraídos por su clase como ciudadanos del estado en igualdad con los demás que se formaran”. 43

La rebelión de los suboficiales Blandengues sobre Viamonte, el 3 de marzo de 1816, hizo que éste se asegurara de mantener a los oficiales que eran de su confianza, "se dispone que las Milicias de Pardos Cívicos sigan con los mismos oficiales ya nombrados, y que se distingan por $3^{\circ}$ y $4^{\circ}$, cuyos capitanes son, por ahora, Pantaleón Reyes y Bartolomé Cámara respectivamente, y dar cuenta de todo al Director y al General del Ejército en esta ciudad". ${ }^{44}$ Cuando los insurgentes habían tomado Santo Tomé, el Ejército de Observación premió a un soldado afrodescendiente: "\$10 al 'soldado pardo heroico patriota' Joaquín Ramírez, prisionero de los sitiadores, que logró fugarse, y que envió el Capitán Pantaleón Reyes, por disposición del General en Jefe para que el cuerpo le expresara su gratitud". 45

Tanto el acuartelamiento como el intento de Viamonte por mantener milicianos pardos de su lado y las disputas que se dieron en el Cabildo en torno a si los oficiales de esta fuerza debían ser convocados para las elecciones, muestran el desarrollo de una politización miliciana de africanos y afrodescendientes en Santa Fe. Fradkin propone que "todas estas prácticas sugieren que dentro del ejército se estaba produciendo una situación que podría describirse como un estado de negociación del mando y del ejercicio de la autoridad" (A 173). Efectivamente, la formación política en las milicias urbanas de la ciudad es probable que haya infundido sobre los soldados pardos y

\footnotetext{
42 “José Manuel Troncoso a Juan Francisco Tarragona”, [Santa Fe, noviembre 11 de 1815], AA, T. XXIX, pp. 286-288.

${ }^{43}$ AGPSF, Actas Recuperadas Caja 2, Acuerdos de 1815, ff. 52v - 53v.

${ }^{44}$ AGPSF, T. XVII, ff. 575-575v.

${ }^{45}$ AGPSF, T. XVII, ff. 576v.-579.
} 
morenos un sentimiento partidario por la autonomía que trataba de defender el Cabildo de Santa Fe.

\section{Conclusión.}

Los africanos y afrodescendientes santafesinos experimentaron una fuerte movilización militar a partir del momento en que Santa Fe entró en la revolución. Sin embargo, la milicia cívica que se formó en 1810 para defender la ciudad no era valorada de la misma manera que las demás, de hecho, se le asignaba un ayudante mayor por la necesidad de adiestramiento que se percibía para los soldados pardos libres, se consultaba si el salario de éstos debía ser igual que para el resto de los reclutados, se les impedía formar parte de la caballería, eran segregados en unidades separadas -no así los indígenas- como si todavía siguieran formando parte del sistema de castas, y se les limitaba el acceso a los cargos superiores de la oficialidad. Esta milicia fue elevada a regimiento en 1813, aunque el aumento del número de plazas que el cambio de estatuto suponía comenzó a operar recién al año siguiente -como lo comprueban las 900 disponibles en 1814 que menciona Fradkin. La medida pareció haber respondido a un cambio de mandos, del Cabildo de Santa Fe a la Comandancia de Buenos Aires, que hacia 1815 dividía el cuerpo en dos compañías.

Estas características podían variar para la compañía auxiliar al Ejército del Perú que se levantó en 1813, ya que, al menos el capitán Mariano Riverola pertenecía a la plana mayor, siendo un pardo libre. Además, la fuerza pertenecía al Ejército del Perú, por lo que era regular y, supuestamente, sus efectivos recibían formación profesional, aunque habría que avanzar en la investigación para constatar si la condición de compañía auxiliar no suponía un limitante para la percepción de fueros y salarios de los soldados. A pesar de que los reclutas pardos y morenos no alcanzaban a gozar en forma verdaderamente igualitaria los beneficios de la veteranía de su cuerpo militar, fueron permanentemente movilizados a partir de 1810 -en la práctica, siempre bajo las condiciones de unidad de milicia- provocando una significativa militarización del grupo étnico afrodescendiente.

Más allá de que los pardos y morenos santafesinos fueron interpelados por el Estado revolucionario, siendo reclutados dentro de estas dos compañías, recibían un trato segregado y se tenía la precaución de que éstos no tuvieran voz y voto en las 
discusiones acerca de las acciones bélicas, por lo que la politización se desarrolló más bien horizontalmente, a partir de la tropa miliciana como ámbito de socialización de las cuestiones de la revolución y la guerra. Las acciones políticas de los soldados africanos y afrodescendientes consistían, muchas veces, en reacciones ante las directivas de los poderes militares, reclamando por la liberación de su capitán, pergeñando un plan para sustraer caballos y municiones y pasarse al bando contrario de la revolución, o resistiendo la degradación de su categoría veterana por parte de un ejército invasor.

El considerable porcentaje de reclutamiento de pardos y morenos en Santa Fe es una marca de su importancia militar en la región. Para 1813, su representación alcanza a casi el 30\% del total de los movilizados en todas las unidades, significando aproximadamente el $47 \%$ de los varones afrodescendientes pasibles de ser reclutados, es decir, 202 de 428, lo cual pudo haber provocado, seguramente, un impacto significativo en la tasa de masculinidad dentro de este grupo étnico.

Es indiscutible que Santa Fe entrañaba un nudo complejo para el tejido de la revolución, siendo Buenos Aires y Montevideo las dos puntas del ovillo. En esta maraña, se entrecruzaban otros hilos por encima, o por debajo, de las autoridades, aunque ineludiblemente enlazados con ellas, mediante los cuales se consagraban identidades en torno a la experiencia militar, como pardos y morenos compañeros de la tropa, y se construían liderazgos que sostenían una red de relaciones sociales. Los contactos de Riverola son un ejemplo del desarrollo de estas redes, que conectaban a Buenos Aires, Santa Fe y Montevideo a través de las relaciones y afinidades que este capitán tenía con líderes políticos de estos espacios.

La politización miliciana los alcanzó por el hecho mismo de su reclutamiento y participación armada en las compañías, pero sus acciones políticas, más que legitimadas, eran prácticas de resistencia contra el poder que los administraba como soldados. Es decir, si bien la militarización los vinculó a una esfera política, como cuerpos militares segregados los batallones de pardos y morenos contaban con bajas posibilidades de actuación. Además, sus condiciones materiales eran poco favorables y su capital político era muy reducido en comparación con el resto de las unidades creadas bajo la revolución. De hecho, cuando en noviembre de 1815 se convocó a los oficiales de las compañías para elegir a los capitulares de 1816, la participación de los 
pardos y morenos dentro de la asamblea electoral supuso reservas y terminaron siendo proscriptos por ser descendientes de hombres esclavizados. Sin embargo, la capacidad de acción de las tropas de africanos y afrodescendientes no era menospreciada entre las autoridades políticas, como lo demuestra la advertencia que Troncoso hace al teniente de gobernador Tarragona de no quitar la veteranía a la compañía de pardos libres de la ciudad, para evitar que los soldados se subleven, como finalmente lo hicieron a fines de 1815 .

Para finalizar, se concluye que tanto la manifestación de los negros de Punta Gorda en 1813, como el acuartelamiento de la milicia cívica de la ciudad en 1815, corresponden a prácticas de participación política durante los años de guerra que comenzaron a vivirse desde 1810 dentro del Litoral. El carácter extremadamente local de las unidades de pardos y morenos de Santa Fe propició a que dichas acciones políticas se identifiquen más fácilmente con los estandartes autonomistas que levantaban los caudillos locales o el movimiento artiguista, siendo generalmente antagonistas al proyecto revolucionario porteño.

\section{Fuentes.}

Archivo General de la Provincia de Santa Fe, Contaduría, Tomos 14, 15 y 16.

AGPSF, Gobierno, Tomo 1.

AGPSF, Cabildo, Documentos Varios.

Archivo General de la Nación (Argentina), Sala X, L. 30-2-2, Sumarios Militares.

Comisión Nacional Archivo Artigas, T. 29

\section{Bibliografía.}

Aramburo, Mariano, Una vinculación diferente. Una aproximación a los afroporteños milicianos en la década de 1810 , en M. Cutrera y M. Pérez (eds.), Autoridades y sujetos entre la colonia tardía y la construcción del estado nacional. Signos en el Tiempo y Rastros en la tierra. Segunda época, vol. 5, Biblos, 2011. 39-66.

Andrews, George R., Los afroargentinos de Buenos Aires. Buenos Aires: Ed. de la Flor. 1989.

Barriera, Darío y Tarragó, Griselda, Tomo IV, Adiós a la monarquía, de los años revolucionarios a la crisis de 1820, en Nueva Historia de Santa Fe. Barriera, D. (Dir.), Rosario: Prohistoria. 2006 
Baravalle, Ma. del Rosario, Los esclavos y la esclavitud, en Nueva Historia de Santa Fe. Tomo III, Economía y sociedad (siglos XVI a XVIII), D. Barriera (Ed.), Rosario: Prohistoria. 2006.

Borucki, Alex, De compañeros de barco a camaradas de armas : identidades negras en el Río de la Plata, 1760-186o. Capítulos tercero y cuarto. A. Borucki (1ra Ed.), Buenos Aires: Prometeo Libros. 2017.

Bragoni, Beatriz, Esclavos insurrectos en tiempos de revolución (Cuyo 1812), en Negros de la Patria: Los afrodescendientes en las luchas por la independencia en el antiguo Virreinato del Río de la Plata, Mallo, S.; Telesca, I. (Eds.), Buenos Aires: Editorial SB. 2010

Candioti, Magdalena, Hacia una historia de la esclavitud y la abolición en la ciudad de Santa Fe, 1810-1853, en Cartografías latinoamericanas. Guzmán, F.; Geler, L.;Frigerio, A. (Ed.), Buenos Aires: Biblos. 2016.

Candioti, Magdalena, Manumisiones negociadas y libertades frágiles en el Río de la Plata. Santa Fe, 1810-1853, en Formas de liberdade: gratidão, condicionalidade e incertezas no mundo escravista nas Américas. Organização J. Freire, Ma. V. Secreto, 1ra ed., Rio de Janeiro: Mauad X: Faperj. 2018.

Candioti, Magdalena et al, Esclavos, libres y libertos en la ciudad de Santa Fe a inicios del siglo XIX. Un análisis demográfico y social a partir del padrón de población de 1816-1817, en Esclavos : una subjetividad negada, M. Ghirardi (Ed.), 1era Edición, Córdoba: Báez Ed. 2019.

Cervera, Manuel, Historia de la Ciudad y Provincia de Santa Fe, 1573-1853, Tomo I, Santa Fe: Librería e Imprenta la Unión. 1908.

Cervera, Manuel, Santa Fe (1810-1820), en Historia de la Nación Argentina, Levene, R. (Dir.), Buenos Aires: El Ateneo. 1946.

Di Meglio, Gabriel, Soldados de la Revolución. Las tropas porteñas en la guerra de independencia (1810-1820), Anuario del IEHS, $\mathrm{n}^{\circ}$ 18, Tandil. 2003.

Di Meglio, Gabriel, Viva el bajo pueblo: la plebe urbana de Buenos Aires y la política entre la revolución de mayo y el rosismo. Capítulo III: "Nuestro sistema": política y guerra (1812-1818). 1ra Edición, Buenos Aires: Prometeo Libros. 2007.

Fradkin, Raúl y Ratto, Silvia, Conflictividades superpuestas. La frontera norte de Buenos Aires a mediados de la década de 1810, en Boletín Americanista, Año LVIII, $n^{0} 58$, Barcelona. 2008.

Fradkin, Raúl, La conspiración de los sargentos. Tensiones políticas y sociales en la frontera de Buenos Aires y Santa Fe en 1816, en Entre la Colonia y la República. Insurgencias, rebeliones y cultura política en América del Sur, Bragoni, B.; Mata, Sara E. (Comp.), Buenos Aires: Prometeo Libros. 2008.

Fradkin, Raúl, Fuerzas militares y milicianas y configuración de un espacio fronterizo (1760-1820), en Gobierno, justicias y milicias: La frontera entre Buenos Aires y Santa Fe (1720-1830). Barriera, D. G. y Fradkin, R. O. (coord.). La Plata: Universidad Nacional de La Plata. (Estudios/Investigaciones; 50). 2016

Gianello, Leoncio, Historia de Santa Fe. Santa Fe: Plus Ultra. 1978. 
Goldberg, Marta, Afrosoldados de Buenos Aires en armas para defender a sus amos, en Negros de la Patria: Los afrodescendientes en las luchas por la independencia en el antiguo Virreinato del Río de la Plata. Mallo, S.; Telesca, I. (Ed.), Buenos Aires: SB Ediciones. 2010.

Guzmán, Florencia, Afroargentinos, guerra y política, durante las primeras guerras del siglo XIX. Una aproximación hacia una historia social de la revolución, en Estudios Históricos, CDHRPyB, Año V, N ${ }^{\circ} 11$, Uruguay. 2013.

Mata, Sara, Negros y esclavos en la guerra por la independencia. Salta 1810-1821, en Negros de la Patria: Los afrodescendientes en las luchas por la independencia en el antiguo Virreinato del Río de la Plata, Mallo, S. y Telesca, I. (Eds.), Buenos Aires: Editorial SB. 2010.

Morrone, Francisco, Los negros en el Ejército: Declinación demográfica y disolución, Buenos Aires: Centro Editor de América Latina. 1995

Rabinovich, Alejandro, La militarización del río de la plata, 1810-1820. Elementos cuantitativos y conceptuales para un análisis, Boletín del Instituto de historia argentina y americana "Dr. Emilio Ravignani", $3^{\circ}$ Serie, $N^{\circ}$ 37. 2012. 11-42

Rabinovich, Alejandro, Ser soldado en las Guerras de Independencia. La experiencia cotidiana de la tropa en el Río de la Plata, 1810-1824, Buenos Aires: Sudamericana. 2013. 